\title{
GAMBARAN NILAI VAS (Visual Analogue Scale) PASCA BEDAH SEKSIO SESAR PADA PENDERITA YANG DIBERIKAN TRAMADOL
}

\author{
Daniel Francis Jaury ${ }^{1}$, \\ Lucky Kumaat ${ }^{2}$, \\ Harold F. Tambajong ${ }^{2}$ \\ ${ }^{1 .}$ Kandidat Skripsi Fakultas Kedokteran Universitas Sam Ratulangi Manado \\ ${ }^{2}$ Bagian Anestesiologi dan Terapi Intensif Fakultas Kedokteran Universitas Sam \\ Ratulangi Manado
}

Email: daniel.jaury@yahoo.com

\begin{abstract}
Visual Analogue Scale (VAS) is an instrument use to measure pain intensity. It is considered as the most efficient and it has been used in research and sensitivity test of analgesic drug. VAS is usually presented as a horizontal line numbered 0 to 10. Tramadol in an opioid analgesic, acts centrally, which has a moderate $\mu$ receptors. This drug has been used to treat light to moderate pain.The aim of this study is to find out the VAS score of the postoperative caesarean section patients, treated with tramadol as the pain reliever. This study is a prospective descriptive study which is done in recovery room of Central Surgical Installation Prof. DR. R. D. Kandou Manado general hospital. As much as 18 women who met the inclusion criteria were observed during this study. Result shows that the mean of VAS I score (2 hours post administered) is 2.4, the mean of VAS II score (4 hours post administered) is 3, and the mean of VAS III score (6 hours post administered) is 3.4.
\end{abstract}

Keywords: VAS, tramadol

\begin{abstract}
Abstrak:Visual Analogue Scale (VAS) merupakan alat pengukuran intensitas nyeri yang dianggap paling efisien yang telah digunakan dalam penelitian dan uji sensitivitas suatu obat analgetik. VAS umumnya disajikan dalam bentuk garis horisontal dan diberi angka 0-10. Tramadol adalah analgetik golongan opioid yang bekerja sentral yang memiliki afinitas sedang pada reseptor $\mu$ yang lemah. Obat ini digunakan sebagai penghilang rasa sakit derajat ringan sampai sedang. Tujuan penelitian ini adalah untuk mengetahui gambaran nilai VAS (Visual Analogue Scale) pasca bedah seksio sesar pada penderita yang diberikan tramadol. Penelitian ini merupakan penelitian deskriptif prospektif yang dilakukan pada ruang pasca bedah (recovery room) Instalasi Bedah Sentral RSUP. Prof. DR. R. D. Kandou Manado dengan subjek penelitian berjumlah 18 orang yang telah memenuhi kriteria inklusi. Dapat disimpulkan bahwa rerata gambaran nilai VAS I (2 jam setelah pemberian obat) adalah 2,4. Nilai VAS II (4 jam setelah pemberian obat) adalah 3. Nilai VAS III (6 jam setelah pemberian obat) adalah 3,4.
\end{abstract}

Kata kunci: VAS, tramadol

Nyeri pasca bedah merupakan permasalahan yang sangat penting dan sering dihadapi oleh pasien pasca bedah. Setiap pembedahan akan menimbulkan konsekuensi nyeri oleh karena kerusakan jaringan ituu sendiri. Nyeri pasca bedah dapat memberikan pengaruh buruk terhadap proses penyembuhan dan waktu pemulihan tubuh pasien. ${ }^{1}$ Survei yang dilakukan oleh Ferdianto terhadap pasien yang menjalani prosedur pembedahan, sekitar $80 \%$ pasien mengalami nyeri pasca bedah , dan $86 \%$ dari pasien tersebut mengalami nyeri sedang sampai berat. $^{2}$ Salah satu jenis pembedahan yang sering dilakukan adalah seksio sesar. ${ }^{3}$ Data dari 
seluruh dunia menunjukkan 15\% kelahiran menggunakan prosedur pembedahan seksio sesar dan $21,1 \%$ berasal dari negara maju. Jumlah ibu yang mengalami nyeri sedang sebesar $28,7 \%$ dan yang mengalami nyeri ringan pasca seksio sesar sebesar $71,43 \% .^{3}$

Untuk menangani nyeri pasca bedah telah disediakan berbagai macam terapi yang disebut dengan terapi multimodal. Terapi multimodal itu termasuk diantaranya penggunaan obat-obat analgetik., ${ }^{2,4}$ Meskipun telah ada kemajuan dalam pemahaman tentang patofisiologi dan farmakoterapi nyeri, namun hingga kini belum ada obat tunggal atau kombinasi obat yang mampu memberikan efektifitas yang tinggi dan efek samping yang minimal. ${ }^{4}$ Penelitian ini bertujuan untuk mengetahui gambaran nilai VAS (Visual Analogue Scale) pasca bedah seksio sesar pada penderita yang diberikan tramadol.

Ada berbagai macam obat yang termasuk dalam golongan opioid yang berkhasiat untuk meredakan dan meringankan nyeri, salah satunya tramadol. Tramadol direkomendasikan oleh WHO untuk mengatasi nyeri kanker karena tramadol aman dan efisien. ${ }^{5}$ Tramadol adalah analgetik yang bekerja secara sentral yang memiliki afinitas sedang pada reseptor $\mu$ yang lemah. ${ }^{6,7}$ Tramadol secara luas digunakan sebagai obat penghilang rasa sakit derajat ringan sampai sedang. ${ }^{8}$ Rumus kimia dari tramadol yaitu 2-[(dimetilamino)metil1-(3-(metoksifenil)-sikloheksanol hidroklirida yang merupakan sintetik dari kelompok aminosikloheksanol yang bersifat agonis opioid. ${ }^{9}$ Tramadol sama efektifnya dengan morfin atau meperidin untuk nyeri ringan sampai sedang tetapi untuk nyeri berat atau kronik lebih lemah. Untuk nyeri persalinan tramadol kurang menyebabkan depresi pernapasan. ${ }^{10}$

Tramadol terikat secara stereospesifik pada reseptor nyeri di sistem saraf pusat, dan menghambat re-uptake noradrenalin dan serotonin dari sistem saraf aferen. ${ }^{9}$ Tramadol yang diberikan secara oral mempunyai bioavailabiltas hingga $70 \%$ sedangkan yang diberikan secara parenteral bioavailabilitas mencapai $100 \% .{ }^{8}$ Tramadol didistribusikan secara cepat dan luas keseluruh tubuh dengan volume distribusi 2-3 liter/kgBB pada dewasa muda. Tramadol melewati sawar darah otak dan plasenta. Metabolisme tramadol terjadi di hati melalui proses glukoronidasi dan di eksresi melalui ginjal. Waktu paruh eliminasi sekitar 5-7 jam.8,10 Terdapat kenaikan tekanan darah setelah pemberian tramadol secara intravena namun tidak mempengaruhi sistem kardiovaskuler. Terjadi peningkatan tahanan vaskuler perifer sebanyak 23\% pada 2-10 menit pertama dan 15-20\% terjadi peningkatan terhadap kerja dari jantung. ${ }^{11}$

Dosis maksimal yang dapat diberikan sebesar $400 \mathrm{mg} / \mathrm{kgBB} / \mathrm{hari}$, dengan sediaan tablet dengan dosis 50-100 mg dapat diberikan 3-4 kali sehari. ${ }^{8}$ Untuk nyeri pasca bedah dianjurkan dosis sebesar $100 \mathrm{mg}$ pertama diberikan secara intravena bolus perlahan 2-3 menit. Dosis selanjutnya 50-100 mg dapat diulang 4-6 jam kemudian. ${ }^{10}$ Tramadol sebaiknya tidak diberikan pada pasien dengan riwayat penyalah gunaan obat walaupun potensi untuk penyalahgunaan belum jelas. Tidak digunakan juga pada pasein yang menggunakan penghambat MAO (moniamine-oksidase) karena efek inhibisisnya terhadap serotonin. Selain itu perlu perhatian khusus pada pasien epilepsi karena salah satu efek dari tramadol dapat menyebabkan kejang maupun kambuhnya serangan kejang. ${ }^{11}$ Efek samping yang bisa timbul dari penggunaan tramadol secara umum adalah mual, muntah, pusing, dan mulut kering.,10

Kontrol nyeri pasca bedah adalah bagian penting dalam manajemen nyeri karena hal ini yang menentukan penggunaan dan pemberian obat analgetik. Pengukuran intensitas nyeri sangat subjektif dan individual. Kemungkinan yang terjadi pada nyeri dalam intensitas yang sama dirasakan sangat berbeda oleh dua orang yang berbeda pula. Oleh sebab itu digunakan alat pengukuran untuk menilai derajat intensitas nyeri secara keseluruhan. ${ }^{6}$ Terdapat 4 alat Unidimentional Pain Rating Scale (UPRS) utama yang digunakan dalam praktek klinis untuk menilai nyeri. Terdiri dari Numeric Rating Scale (NRS), Verbal Rating Scale (VRS), Faces Pain Scale (FPS) dan Visual Analogue Scale (VAS). ${ }^{12}$ 
Visual Analogue Scale (VAS) merupakan alat pengukuran intensitas nyeri yang dianggap paling efisien yang telah digunakan dalam penelitian dan pengaturan klinis. ${ }^{6}$ VAS umumnya disajikan dalam bentuk garis horisontal. ${ }^{6}$ Dalam perkembangannya VAS menyerupai NRS yang cara penyajiannya diberikan angka 0-10 yang masing-masing nomor dapat menunjukkan intensitas nyeri yang dirasakan oleh pasien. ${ }^{13}$ Dalam beberapa penelitian yang dilakukan untuk menilai intensitas nyeri pasca operasi, skala yang digunakan adalah rekombinasi antara VAS dan NRS. ${ }^{13}$ VAS juga sering digunakan untuk menilai nyeri pada pasien untuk dapat memperoleh sensitivitas obat pada uji coba obat analgetik. ${ }^{14}$ Dalam penggunaan VAS terdapat beberapa keuntungan dan kerugian yang dapat diperoleh. Keuntungan penggunaan VAS antara lain VAS adalah metode pengukuran intensitas nyeri paling sensitif, murah dan mudah dibuat. ${ }^{13}$ VAS mempunyai korelasi yang baik dengan skalaskala pengukuran yang lain dan dapat diaplikasikan pada semua pasien serta VAS dapat digunakan untuk mengukur semua jenis nyeri. ${ }^{6}$ Namun kekurangan dari skala ini adalah VAS memerlukan pengukuran yang lebih teliti dan sangat bergantung pada pemahaman pasien terhadap alat ukur tersebut. ${ }^{13,15}$

\section{METODE}

Penelitian ini bersifat deskriptif prospektif yang dilakukan diruang perawatan pasca bedah (recovery room) Instalasi Bedah Sentral (IBS) RSUP. Prof. DR. R. D. Kandou Manado mulai bulan November 2013 hingga Desember 2013. Sampel penelitian adalah pasien pasca bedah seksio sesar yang memenuhi kriteria inklusi dan telah menandatangani lembar persetujuan (informed consent) untuk ikut dalam penelitian. Adapun kriteria inklusi dari penelitian yaitu umur 20-40 tahun, status fisik ASA I-II, pasien dengan lama operasi 1-2 jam, jenis anestesi dengan teknik anestesi lokal (spinal anastesi) dengan menggunakan obat analgetik tramadol. Kriteria eksklusi dari penelitian ini adalah pasein dengan komplikasi pasca bedah, mengeluh nyeri pada saat mulai operasi, pasien yang menolak untuk ikut serta dalam penelitian serta pasien dengan riwayat penyalahgunaan obat. Kriteria drop out dari penelitian ini adalah apabila selama operasi terjadi efek samping yang hebat dan selama intraoperasi terdapat masalah serius (mis: pendarahan masif) sehingga membutuhkan konversi teknik anestesi. Pengambilan sampel penelitian dilakukan dengan metode purposive sampling dimana kelompok populasi dipilih berdasarkan kemauan peneliti bahwa individu tersebut adalah sesuai dan cocok untuk dijadiakan sampel penelitian.

Pelaksanaan penelitian ini dilakukan pada penderita yang memenuhi kriteria ikut dalam penelitian menjalani prosedur persiapan operasi seksio sesar yang berlaku. Pasien dijelaskan maksud dan tujuan penelitian serta meminta persetujuan kepada pasien untuk dilakukan penelitian (tanda tangan informed consent). Dijelaskan juga kepada pasien cara penggunaan skor nyeri (VAS) dimana nantinya pasien akan menentukan seberapa berat nyeri yang ia rasakan pada saat itu.

Pada saat operasi. semua subjek mendapat anestesi menggunakan teknik spinal anestesi dengan Bupivacain 0,5\% di interspace L3-L4. Lama operasi dicatat pada lembar pengamatan. Setalah operasi, bolus secara perlahan lahan tramadol 100 mg selama 2-3 menit. Pasca bedah pasien kemudian dibawa ke ruang pemulihan (recovery room). Setelah pemberian bolus tramadol I.V pasien diobservasi setiap 2 jam di hitung pada saat akhir pemberian dari obat tramadol hingga 6 jam setelah pemberian obat.

\section{HASIL DAN PEMBAHASAN}

Penelitian yang dilakukan di bagian Anestesiologi dan Terapi Intensif khususnya Instalasi Bedah Sentral (IBS) RSUP Prof. DR. R.D. Kandou Manado pada bulan November 
2013 sampai Desember 2013 merupakan penelitian yang bersifat deskriptif prospektif. Dalam rentang waktu tersebut diperoleh 18 kasus yang dilakukan operasi seksio sesar dengan mengunakan anestesi lokal (spinal anestesi) dan obat analgetik tramadol.

Berdasarkan tabel 1, jumlah kasus seksio sesar dengan anestesi lokal (spinal anestesi) paling banyak didapatkan pada kelompok umur 31-40 tahun sebanyak 8 kasus (44,44\%). Kemudian pada kelompok umur 20-30 tahun sebanyak 7 kasus (38,89\%) dan pada kelompok umur $>40$ tahun sebanyak 3 kasus (16,67\%). Tingginya proporsi ibu bersalin dengan seksio sesar pada kelompok 20-35 tahun merupakan kelompok umur reproduktif yang optimal bagi ibu untuk hamil dan melahirkan.

Tabel 1. Distribusi pasien berdasarkan umur

\begin{tabular}{cccc}
\hline \multirow{2}{*}{ NO } & Kelompok Umur & \multicolumn{2}{c}{ Jumlah } \\
\cline { 3 - 4 }$($ tahun) & $\mathrm{N}$ & $\%$ \\
$\mathbf{1}$ & $20-30$ & 7 & 38.89 \\
$\mathbf{2}$ & $31-40$ & 8 & 44.44 \\
$\mathbf{3}$ & $>40$ & 3 & 16.67 \\
Jumlah & & 18 & 100 \\
\hline
\end{tabular}

Sumber : Data Primer

Berdasarkan tabel 2, diperoleh hasil bahwa dari 18 sampel didapatkan pasein dengan kelompok berat badan $<70$ kilogram sebanyak 9 orang (50\%), kelompok berat badan 70-100 kilogram sebanyak 8 orang (44.44\%), dan kelompok berat badan $>100$ kilogram sebanyak 1 orang (5.56\%).

Tabel 2. Distribusi pasien berdasarkan berat badan

\begin{tabular}{cccc}
\hline NO & Kelompok Berat & \multicolumn{2}{c}{ Jumlah } \\
\cline { 3 - 4 } & Badan (kilogram) & $\mathrm{N}$ & $\%$ \\
$\mathbf{1}$ & $<70$ & 9 & 50 \\
$\mathbf{2}$ & $70-100$ & 8 & 44.44 \\
$\mathbf{3}$ & $>100$ & 1 & 5.56 \\
Jumlah & & 18 & 100 \\
\hline
\end{tabular}

Sumber: Data Primer

Berdasarkan tabel 3, dari segi lama operasi ditemukan rata-rata 82,22 menit dari 18 pasien yang menjadi sampel. Dimana kelompok pasien yang lama operasi $<75$ menit terdapat 
3 pasien (16,67\%), kelompok pasein yang lama operasi 75-90 menit terdapat 13 pasien (72,22\%) dan kelompok pasien yang lama operasi >90 menit terdapat 2 pasien $(11,11 \%)$.

Tabel 3. Distribusi pasien berdasarkan lama operasi

\begin{tabular}{cccc}
\hline NO & Kelompok Lama & \multicolumn{2}{c}{ Jumlah } \\
\cline { 3 - 4 } & Operasi (menit) & $\mathrm{N}$ & $\%$ \\
$\mathbf{1}$ & $<75$ & 3 & 16.67 \\
$\mathbf{2}$ & $75-90$ & 13 & 72.22 \\
$\mathbf{3}$ & $>90$ & 2 & 11.11 \\
Jumlah & & 18 & 100 \\
\hline
\end{tabular}

Sumber: Data Primer

Berdasarkan tabel 4, diperoleh hasil bahwa dari 18 sampel didapatkan pasien yang mempunyai nilai VAS 2 pada saat 2 jam setelah pemberian obat sebanyak 11 orang (61.11\%) dan pasein yang mempunyai nilai VAS 3 pada saat 2 jam setelah pemberian obat sebanyak 7 orang (38.89\%). Pasien yang mempunyai nilai VAS 2 pada saat 4 jam setelah pemberian obat sebanyak 2 orang (11.11\%) dan pasien yang mempunyai nilai VAS 3 pada saat 4 jam setelah pemberian obat sebanyak 16 orang (88.89\%). Pasien yang mempunyai nilai VAS 3 pada saat 6 jam setelah pemberian obat sebanyak 10 orang (55.56\%) dan pasien yang mempunyai nilai VAS 4 pada saat 6 jam setelah pemberian obat sebanyak 8 orang (44.44\%).

Tabel 4. Distribusi pasien berdasarkan nilai VAS

\begin{tabular}{cccc}
\hline \multirow{2}{*}{ Jam } & VAS & \multicolumn{2}{c}{ Jumlah } \\
\cline { 2 - 4 } \multirow{2}{*}{$\mathbf{2}$ jam } & 2 & 11 & $\%$ \\
\multirow{2}{*}{4 jam } & 3 & 7 & 61.11 \\
\multirow{2}{*}{$\mathbf{6}$ jam } & 2 & 2 & 38.89 \\
& 3 & 16 & 11.11 \\
& 3 & 10 & 88.89 \\
& 4 & 8 & 55.56 \\
\end{tabular}

Rerata dari nilai VAS I (2 jam setelah pemberian obat) ditemukan nilai sebesar 2,4 dimana dari 18 pasien yang mempunyai nilai VAS=2 pada saat 2 jam setelah pemberian obat tramadol sebanyak 11 orang $(61,11 \%)$ dan pasien yang mempunyai nilai VAS $=3$ pada saat 2 jam setelah pemberian obat tramadol sebanyak 7 orang (38,89\%). Rerata dari nilai VAS II (4 jam setelah pemberian obat) ditemukan nilai sebesar 3 dimana dari 18 pasien yang mempunyai nilai VAS=2 pada saat 4 jam setelah pemberian obat tramadol sebanyak 2 orang $(11,11 \%)$ dan pasien yang mempunyai nilai VAS=3 pada saat 4 jam setelah pemberian obat 
tramadol sebanyak 16 orang (88,89\%). Rerata dari nilai VAS III (6 jam setelah pemberian obat) ditemukan nilai sebesar 3,4 dimana dari 18 pasien yang mempunyai nilai VAS=3 pada saat 6 jam setelah pemberian obat tramadol sebanyak 10 orang $(55,56 \%)$ dan pasien yang mempunyai nilai VAS $=4$ pada saat 4 jam setelah pemberian obat tramadol sebanyak 8 orang $(44,44 \%)$.

\section{KESIMPULAN}

Berdasarkan hasil penelitian yang dilakukan di bagian Anestesiologi dan Terapi Intensif khususnya di bagian Instalasi Bedah Sentral (IBS) RSUP. Prof. DR. R. D. Kandou Manado pada bulan November 2013 sampai dengan Desember 2013 mengenai gambaran nilai VAS (Visual Analogue Scale) pasca bedah seksio sesar pada penderita yang diberikan tramadol, dapat disimpulkan bahwa:

1. Hasil penelitian dan pengamatan pada pasien pasca bedah seksio sesar yang diberikan tramadol menunjukkan rata-rata nilai VAS setelah 2 jam pemberian tramadol adalah 2,4 dari total sampel yang ada.

2. Hasil penelitian dan pengamatan pada pasien pasca bedah seksio sesar yang diberikan tramadol menujukkan rata-rata nilai VAS setelah 4 jam pemberian tramadol adalah 3 dari total sampel yang ada.

3. Hasil penelitian dan pengamatan pada pasien pasca bedah seksio sesar yang diberikan tramadol menunjukkan rata-rata nilai VAS setelah 6 jam pemberian tramadol adalah 3,4 dari total sampel yang ada.

\section{SARAN}

Setelah melakukan penelitian ini, maka ada beberapa hal yang perlu diusulkan yaitu:

1. Disarankan buat peneliti selanjutnya agar dilakukan upaya untuk membandingkan penggunaan obat tramadol dengan obat analgetik lain agar supaya dapat mengetahui lebih mendalam tentang efek dan cara kerja dari obat tramadol.

2. Disarankan buat peneliti selanjutnya agar dapat lebih memahami dan mengerti penggunaan VAS serta dapat menbandingkan dengan skala penilaian nyeri yang lain.

3. Perlunya penelitian lebih lanjut dan lebih mendalam agar supaya dapat memperoleh hasil yang lebih tepat dan lebih akurat.

\section{DAFTAR PUSTAKA}

1. Apfelbaun JL, Chen C, Metita SS, Gan TJ. Result from a National Surgery Suggest Postoperative Pain Continues to be Undermanaged. Anesthesia \& Analgesia. 2003;97:534-40.

2. Ferdianto. Rasionalitas Pemberian Analgetiik Tramadol Pasca Operasi di RS Dr. Kariadi Semarang [skripsi].[Semarang]: Fakultas Kedokteran Universitas Diponegoro: 2007.

3. McMaarrow RC, Mhuircheartaigh RJ, Ahmed KA, Aslani A, Ng SC, Martin IC, et al. Comparison of Transversus Andominalis Plane Block vs Spinal Morphine for Pain Relief after Caesarean Section. British Journal Anaesthesia. 2011;106:706-12.

4. Chandrakatan A, Glass PS. Multimodal for Postoperative Nausea and Vomiting and Pain. British Journal Anaesthesia. 2011;107:127-140.

5. Satriyasa BK. Penggunaan Klinik Tramadol. Majalah Kedokteran Udayana. 2001;32. 
6. Breivik H, Borchgrevink PC, Allen SM, Rosseland LA, Romundstad L, Hals EK, et al. Assessment of Pain. British Journal Anaesthesia. 2008;101:17-24.

7. Ifar IY, Hari HS, Himawan S. Obat-obat Anti Nyeri. Jurnal Anestesiologi Indonesia. 2011;3:194-5.

8. Kalant H, Grant DM, Mitchell J, editors. Principle of Medical Farmacology. $7^{\text {th }}$ ed. Canada: Elsevier: 2006.ch.19.p.249.

9. Wojciech L. Tramadol As an Analgesic for Mild to Moderate Cancer Pain. Pharmacological Reports. 2009;61:978-92.

10. Dewoto HR. Analgesik Opioid dan Antagonis. In: Gunawan SG, Setiabudy R, Nafrialdi, Elysabeth editors. Farmakologi dan Terapi. $5^{\text {th }}$ ed. Jakarta: Balai Penerbit FKUI: 2008.p.210-29.

11. Heribertus DA. Perbandingan Efektivitas Antara Ketamin dan Tramadol terhadap Nyeri Penyuntikan Propofol pada Induksi Anestesia [skripsi].[Surakarta]: Fakultas Kedokteran Universitas Sebelas Maret: 2009.

12. Francesca F, Bader P, Echtle D, Giunta F, Williams J. Guidelines on Pain Management. European Association of Urology. 2007.

13. Hawker GA, Mian S, Kendzerska T, French M. Measures of Adult Pain. Arthritis Care \& Research. 2011;63:240-52.

14. Karsten P, Kucukdeveci AA, Tennant A. The Use of The Visual Analogue Scale (VAS) in Rehabilitation Outcomes. J Rehabil Med. 2012;44:609-10.

15. Hartwig MS, Wilson LM. Nyeri. In: Hartanto H, Susi M, Wulansari P, Mahanani DA editors. Patofisiologi Konsep Klinis Proses-Proses Penyakit. $6^{\text {th }}$ ed. Jakarta: ECG: 2005.p.1063-89. 